\title{
Konsol Palplanş Duvarların Gömme Derinliklerinin Lineer Regresyon Analizi ile Tahmini
}

\author{
Recep Akan \\ Süleyman Demirel Üniversitesi, Mühendislik Fakültesi, İnşaat Mühendisliği Bölümü, Isparta, Türkiye, (ORCID: 0000-0002-9277-1659), recepakan@hotmail.com
}

(1st International Conference on Applied Engineering and Natural Sciences ICAENS 2021, November 1-3, 2021)

(DOI: 10.31590/ejosat.1015292)

ATIF/REFERENCE: Akan, R. (2021). Konsol Palplanş Duvarların Gömme Derinliklerinin Tahmini. Avrupa Bilim ve Teknoloji Dergisi, (28), 1336-1341.

\section{$\ddot{O} \mathbf{z}$}

Palplanş duvarlar geoteknik mühendisliği uygulamalarında, özellikle kazı sonucunda meydana gelen yanal toprak basınçlarını karşılamak için yaygın olarak kullanılan istinat yapılarıdır. Konsol palplanş duvarların tasarımında gerekli gömme derinliğinin (D) ve palplanş kesitine etkiyecek maksimum eğilme momentinin(Mmax) hesaplanması gereklidir. İnşaat mühendisliği uygulamalarında, gömme derinliğinin (D) belirlenebilmesi için yanal toprak basınçlarının belirlenmesi ve üçüncü dereceden bir denklem çözülmesi gerekmektedir. Bu çalışma kapsamında, konsol palplanş duvarlarda gömme derinliğinin tahmini için ifade elde edilmiştir. Çoklu regresyon analizi ile elde edilen ifade ile gömme derinliğinin başarılı şekilde tahmin edilebildiği görülmüsşür.

\section{The Prediction of Embedment Depth of Cantilever Sheet Piles Using Linear Regression Analysis}

\begin{abstract}
Sheet pile walls are commonly used retaining structures in geotechnical engineering applications, especially to meet the lateral earth pressures that occur as a result of excavation. In the design of cantilever sheet pile walls, it is necessary to calculate the required embedment depth (D) and the maximum bending moment (Mmax) that will affect the sheet pile section. In civil engineering applications, lateral earth pressures must be determined and a third-order equation must be solved in order to determine the embedment depth (D). Within the scope of this study, an expression for the estimation of embedment depth in cantilever sheet pile walls was obtained. It has been seen that the embedding depth can be successfully estimated with the expression obtained by multiple regression analysis.
\end{abstract}

Keywords: Cantilever sheet pile, Embedment depth, Multiple regression analysis, Excavation 


\section{Giriş}

Palplanş duvarlar geoteknik mühendisliği uygulamalarında, özellikle kazı sonucunda meydana gelen yanal toprak basınçlarını karşılamak için yaygın olarak kullanılan istinat yapılarıdır. Zemin özelliklerine, kazı derinliğine ve uygulama tipine bağlı olarak konsol duvarlar veya dışarıdan desteklenen duvarlar şeklinde olarak kullanılırlar. Palplanş duvarlar genellikle çelik olmak üzere ahşap veya betonarme olarak da inşa edilebilirler. Çelik palplanş duvarlar, birbirine geçen kenarlara sahiptirler ve bu sayede bütün bir duvar gibi çalışabilirler, su geçirimsizliği sağlarlar.

Konsol palplanş duvarlar, 5 - 6 m'ye kadar olan yükseklikler için kullanılırlar ve daha ötesinde dolgu tarafından daha fazla pasif direnç sağlamak için palplanş duvarlara ankrajlar tutturulur. Kalıcı yapılar olan istinat duvarlarından farklı olarak, palplanş duvarlar toprak kütlesini yanal olarak genellikle geçici olarak desteklemek için inşa edilir. Ayrıca palplanş duvarlar istinat duvarların aksine rijit değil esnek yapılardır. Kazı yüzeyinin hemen bitişiğinde herhangi bir yapının mevcut olduğu durumlarda palplanş duvarlar en iyi seçimdir.

Palplanş duvarlar, altmış yıldan fazla bir süredir araştırma alanı olmuştur. Gömülü duvarlar üzerinde model çalışmaları yapan çalışmalardan bazıları Rowe(1951), Bransby ve Milligan(1975) tarafından yapılmıştır. Rowe(1952), sürşarj yük, ankrajların konumu, kazı seviyesi, zemin tipi, duvar esnekliği ve zemin basıncının esnek istinat duvarı üzerindeki dağılımı gibi farklı parametrelerin esnek istinat duvarları üzerine etkisini incelemiştir.

Konsol palplanş duvarların tasarımında gerekli gömme derinliğinin (D) ve palplanş kesitine etkiyecek maksimum eğilme momentinin(Mmax) hesaplanması gereklidir. Mevcut inşaat mühendisliği uygulamalarında yaygın olarak Rankine toprak basınçları teorisine dayalı yaklaşık yöntem ile elde edilen bu değerlerin hesaplanmasında kullanılan birçok teorik yöntemin yanında, daha kolay tahmin edilebilecek ampirik ve yarı ampirik yöntemler mevcuttur (Coduto, 2001; Das, 2007). Palplanş duvarların normalleştirilmiş gömme derinlikleri için ilişkiler daha önce yayınlanmış olan çalışmalarda incelenmiştir (Bolton, Powrie \& Symons, 1990a, 1990b, 1989; Choudry, Singh \& Goel, 2006; Hagerty \& Nofal, 1992). Bolton, Powrie \& Symons(1990a, 1990b, 1989), konsol ve destekli palplanş duvarlar için normalleştirilmiş gömme derinlikleri için drenajsız kayma mukavemeti (kohezyonlu zeminler için) ve sürtünme açısına (kohezyonsuz zeminler için) bağlı tasarım çizelgeleri sunmuştur. Hagerty \& Nofal(1992), kumlu zeminlere gömülen ankrajlı palplanş duvarlar için normalleştirilmiş gömme derinliği ve ankraj kuvveti için basitleştirilmiş tasarım çizelgeleri sağlamıştır. Choudry \& ark.(2006), yatay hat çizgisel yüke maruz kalan palplanş duvarların gömme derinliklerini hesaplamak için normalleştirilmiş ilişkiler sunmuştur. Gajan(2011), kohezyonsuz zeminlere gömülü palplanş duvarların ve kazıklı duvarların gömme derinliklerini hesaplamak için normalleştirilmiş, boyutsuz ilişkiler sunmuştur.

Bunun yanında Akbay ve ark.(2020), betonarme bir istinat duvarının tasarımıla ilgili bir ifade elde edebilmek, Choi \& Lee(2010), istinat duvarı seçimi için bir karar şeması elde etmek, Srivastava \& Malhotra(2016), istinat duvarına etkiyen aktif ve pasif yatay toprak basınçlarını tahmin etmek ve Dagdeviren \& Kaymak(2020), T biçimli bir istinat duvarına ön boyutlandırma önerisi elde etmek amaciyla regresyon analizinden istifade etmişlerdir.
Konsol palplanş duvarların gömme derinliklerinin bulunabilmesi için duvarlara etkiyen yatay yükler belirlendikten sonra duvarın tabanında momentin sıfır olması eşitliğine dayanan üçüncü dereceden bir denklemin kökü elde edilir. Bu çalışma kapsamında bu işlemi basit hale getirebilecek bir ifade elde edilmeye çalışılmış ve bu amaçla sadece arka yüzünde su basıncına maruz kalan kum bir zemine çakılan konsol palplanş duvar için gerekli gömme derinliği çoklu regresyon yöntemi ile tahmin edilmeye çalışılmıştır. Bu amaçla 2106 farklı modele sahip zemine ankstre palplanş çözümü Matlab R2015a yardımıyla gerçekleştirilerek sonuçlar SPSS Statistics v17.0 yardımıyla çoklu regresyon analizine tabi tutulmuş ve palplanş için gerekli gömme derinliğinin tahmin edilebilmesi için ifadeler elde edilmiştir.

\section{Materyal ve Metot}

Çalışma kapsamında, toplam 2106 adet konsol palplanş duvar modelinin çözümleri Matlab R2015a yardımıyla gerçekleştirilmiş ve sonuçlar SPSS Statistics v 17.0 yardımıyla adım adım çoklu regresyon analizi gerçekleştirilerek gömme derinliğini tahmin edebilmek için denklemler elde edilmiştir. Elde edilen ifadelerin tahmin başarıları regresyon katsayısı $\mathrm{R}^{2}$ ve bunun yanında ortalama mutlak relatif hata (MARE) ile belirlenmiştir. Kurulan modeller, bunlara ait ifadeler ve bu ifadelerin tahmin başarısına ait değerlendirme bilgileri tablolar halinde sunulmuştur. En yüksek düzeltilmiş regresyon katsayısına, $\mathrm{R}^{2}$, sahip modellere ait saçılım grafikleri de gösterilmiştir.

\subsection{Konsol Palplanşlar}

Yapılan deneysel çalışmalarda konsol palplanş duvarların O gibi bir noktadan dönme davranışı gösterdikleri ve dolayısıyla bu noktanın alt kısmında aktif ve pasif toprak basınçlarının yer değiştirdikleri gözlenmiştir (Das, 2014). Bu durumda oluşacak toprak basınçları Şekil 1' deki gibi gösterilebilir.

Çalışma kapsamında, çözümü daha basit hale getirebilmek için yaklaşık analiz yöntemi kullanılmıştır. Yaklaşık analizde, duvarın arkasındaki aktif basınç dağılımı ve duvar önündeki pasif basınç dağılımının $\mathrm{O}$ noktasına kadar etkidiği, O noktasının altındaki aktif ve pasif kuvvetlerin O noktasında bir bileşke olarak etkidiği kabul edilir (Sitharam, 2013). Bu kabul ile bulunan D değeri \%20 artırılarak O noktasının altında kalan uzunluk dikkate alınmış olur (Powrie, 1997). Şekil 2' de yaklaşık analiz yöntemine ait yatay toprak basınç dağılımları gösterilmiştir.

Rankine(1857) teorisine göre, aktif ve pasif yanal toprak basınç katsayıları sırasıyla şu şekilde elde edilebilir (Denklem 12):

$$
\begin{aligned}
K a & =\frac{1-\sin (\phi)}{1+\sin (\phi)} \\
K p & =\frac{1+\sin (\phi)}{1-\sin (\phi)}
\end{aligned}
$$

Burada $\phi$, zeminin sürtünme açısıdır.

Rankine teorisini ve duvarın tabanı etrafındaki moment dengesini kullanarak, konsol palplanş duvarlar için aktif ve pasif toprak basınçları ile duvar tabanında kurulan moment dengesi aşağıdaki ifadeler ile elde edilebilir (Denklem 3-5). 


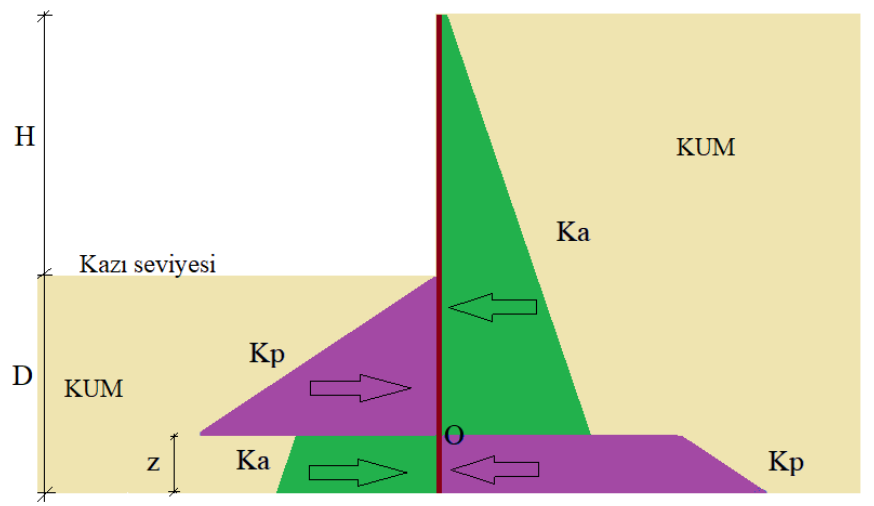

Şekil 1. Konsol palplanş duvara etkiyen yanal toprak kuvvetleri

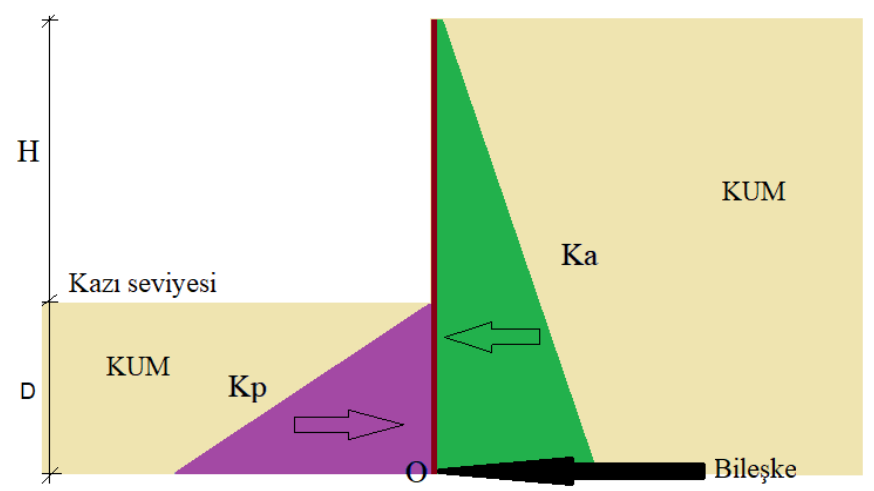

Şekil 2. Yaklaşık yöntemde kabul edilen yanal toprak kuvvetleri

$$
\begin{aligned}
& \mathrm{Pa}=\frac{1}{2} \cdot \gamma^{\prime} \cdot(\mathrm{H}+\mathrm{D})^{2} \cdot K a \\
& \mathrm{Pp}=\frac{1}{2} \cdot \gamma^{\prime} \cdot \mathrm{D}^{2} \cdot K p \\
& K a \cdot(\mathrm{H}+\mathrm{D})^{3}=K p \cdot \mathrm{D}^{3}
\end{aligned}
$$

Burada, H, kazı derinliğini, $\mathrm{D}$, gömme derinliğini göstermektedir. Ayrıca $\gamma^{\prime}$, zeminin efektif birim ağırlı̆̆ını göstermektedir ve Denklem 6 yardımıyla bulunabilir. Çalışma kapsamında suyun birim hacim ağırlı̆̆,$\quad \gamma_{w}=9.81 \mathrm{kN} / \mathrm{m} 3$ alınmıştır.

$$
\gamma^{\prime}=\gamma_{d}-\gamma_{w}
$$

\subsection{Model}

Çalışma kapsamında, kum bir zemine gömülü konsol çalışan bir palplanş duvarın çözümleri gerçekleştirilmiştir. Çözümü gerçekleştirilen modellerde kum zeminin içsel sürtünme açısı, $\phi$, için 20 ile 45 aralı̆̆ında birer artan değerler; kazı derinliği, $\mathrm{H}, 2 \mathrm{~m}$ ile $6 \mathrm{~m}$ arasında; yeraltı su seviyesi (YASS), L1 ile temsil edilmiş ve $0 \mathrm{~m}$ ile $6 \mathrm{~m}$ arasında $0.5 \mathrm{~m}$ aralıklı değerler kullanılmıştır. YASS üzerinde kalan zemin birim hacim ağırlığı, $\gamma_{n}=19 \mathrm{kN} / \mathrm{m}^{3}$ ve YASS altında kalan zeminin doygun birim hacim ağırlığ $\gamma_{d}=21 \mathrm{kN} / \mathrm{m}^{3}$ olarak alınmıştır. İlgili modele ait şematik gösterim Şekil 3' te sunulmuştur.

Oluşturulan modelde meydana gelecek aktif ve pasif yanal toprak basınçları ile hidrostatik su basıncı Şekil 4' teki gibi olacaktır. Bu durumda aktif toprak basıncın bileşenleri ( $\left(\mathrm{P}_{\mathrm{A} 1}, \mathrm{P}^{\prime}{ }_{\mathrm{A} 2}\right.$, $\mathrm{P}^{\prime}{ }_{\mathrm{A}}, \mathrm{P}^{\prime}{ }_{\mathrm{A} 4}, \mathrm{P}_{\mathrm{A} 5}$ ), pasif toprak basınç kuvveti, $\mathrm{P}{ }_{\mathrm{P}}$, hidrostatik su basıncı, $P_{w}$, ve moment dengesi aşağıdaki ifadeler ile elde edilebilir (Denklem 7-14). Moment dengesinden elde edilen üçüncü dereceden denklemin pozitif kökü bulunarak palplanş duvarın gömme derinliği bulunur.

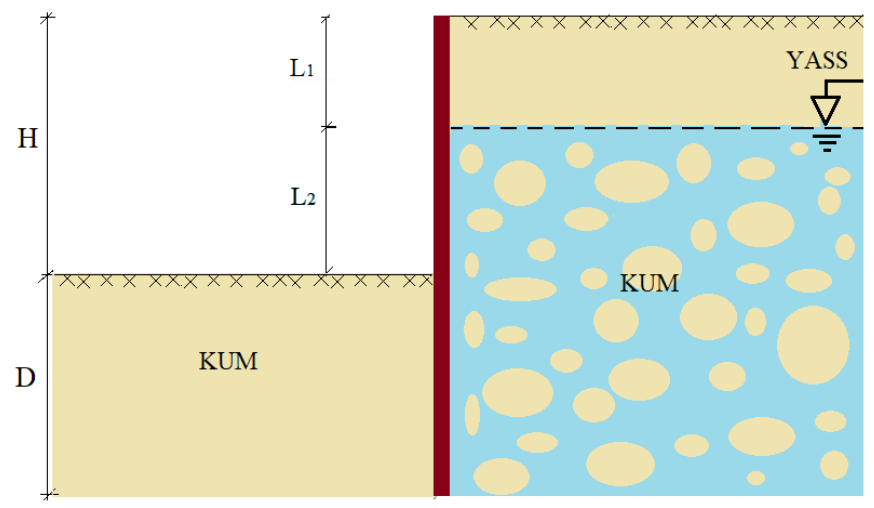

Şekil 3. Çalışmada kullanılan zemin profili ve konsol palplanş duvar modeli

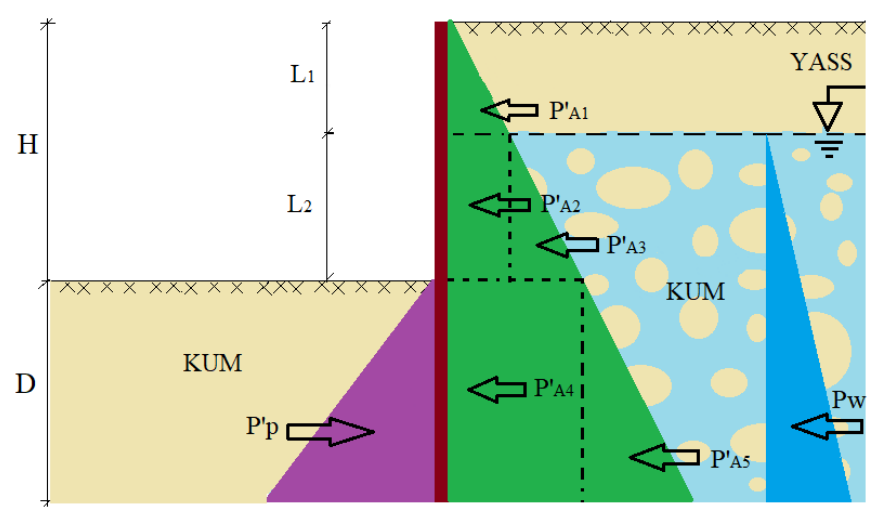

Şekil 4. Çalışmada kurulan modele etkiyen yanal kuvvetler ve bileşenleri

$$
\begin{aligned}
& P_{A 1}^{\prime}=\frac{1}{2} K a \gamma_{n} L_{1}^{2} \\
& P^{\prime}{ }_{A 2}=\gamma_{n} K a L_{1} L_{2} \\
& P^{\prime}{ }_{A 3}=\frac{1}{2} K a \gamma^{\prime} L_{2}^{2} \\
& P^{\prime}{ }_{A 4}=K a D\left[L_{1} \gamma_{n}+L_{2} \gamma^{\prime}\right] \\
& P^{\prime}{ }_{A 5}=\frac{1}{2} K a \gamma^{\prime} \\
& P_{P}^{\prime}=\frac{1}{2} K p \gamma^{\prime} D^{2} \\
& P_{W}=\frac{1}{2} \gamma_{w}\left(D+L_{2}\right)^{2} \\
& P_{A 1}^{\prime}\left(D+L_{2}+\frac{L_{1}}{3}\right)+P^{\prime}{ }_{A 2}\left(D+\frac{L_{2}}{2}\right)+P^{\prime}{ }_{A 3}\left(D+\frac{L_{2}}{3}\right)+ \\
& \frac{1}{2} K a D^{2}\left[L_{1} \gamma_{d}+L_{2} \gamma^{\prime}\right]+\frac{1}{6}(K a-K p) \gamma^{\prime} D^{3}+\frac{1}{6} \gamma_{w}(D+ \\
& \left.L_{2}\right)^{3}=0
\end{aligned}
$$

\section{3. Çoklu Regresyon Analizi}

İstatistikte sıklıkla kullanılan regresyon analizi, regresyon kullanımı ile veriler arasındaki doğrusal korelasyonları matematiksel olarak tahmin eder (Olmschenk, Zhu \& Tang, 2019). Değişken olarak bağımsız değişkenler (neden) ve bağımlı değişkenler (sonuç) kullanılmaktadır (Sato-Ilic, 2017). Bağımlı değişkeni bağımsız değişkenlerin nasıl etkilediğini keşfetmek ve aralarındaki neden-sonuç ilişkisini analiz etmek için regresyon 
analizi tekniği kullanılmaktadır (Chantana ve ark., 2019; Zhang \& Thomas, 2012). Regresyon analizi, bağımsız değişken sayısına göre basit regresyon analizi ve çoklu regresyon analizi olarak ikiye ayrılır. Basit regresyon analizinde bir bağımsız değişken ve bir bağımlı değişken vardır ve aralarında neden-sonuç ilişkisi vardır. Çoklu regresyon analizlerinde bir bağımlı değişken ve en az iki bağımsız değişken vardır. Genel bir çoklu regresyon denklemi aşağıdaki gibidir (Denklem 15).

$$
\mathrm{Y}=\beta_{0}+\beta_{1} X_{1}+\beta_{2} X_{2}+\ldots \ldots+\beta_{n} X_{n}+\varepsilon
$$

Denklemde $\mathrm{Y}$, bağımlı bir değişken ve $\mathrm{X}$, bağımsız bir değişken anlamına gelirken $\varepsilon$, hata terimidir.

Bir regresyon denkleminde değişkenler arasındaki ilişkiyi yargılamak için kriter, regresyon katsayısıdır $\left(\mathrm{R}^{2}\right)$ (Polat, 2015). $\mathrm{Bu}$ katsayı, bir regresyon denkleminin doğruluğunu ve bağımlı değişken için bağımsız bir değişkenin etkisini yargılamayı mümkün kılar. $\mathrm{Bu}$ nedenle, bağımlı ve bağımsız değişkenler arasındaki ilişki, çeşitli analiz koşullarında belirleme katsayısı ile değerlendirilir. Çalışmada ayrıca ikinci bir değerlendirme kriteri olarak ortalama mutlak relatif hata (MARE) kullanılmıştır. Bu değerlendirme kriteri tahmin edilen ve hesapla bulunan gömme derinlikleri arasındaki hatayı yüzde cinsinden vermektedir ve aşağıdaki denklem ile bulunur (Denklem 16).

$\operatorname{MARE}=\frac{1}{n} \sum_{t=1}^{n}\left|\frac{T_{t}-H_{t}}{H_{t}}\right| \times 100$

\section{n : Değerlendirilen veri sayısı \\ $\mathrm{T}_{\mathrm{t}}:$ Tahmin edilen değer \\ $\mathrm{H}_{\mathrm{t}}$ : Hesaplanan değer}

Bu çalışmada, palplanş duvarların gömme derinliklerinin ve bu derinliklerin kazı derinliğini tahmin etmeye yönelik iki farkı model kurulmuştur ve çoklu regresyon analizleri gerçekleştirilmiştir. İlk modelde bağımlı değişken gömme derinliği, D, iken ikinci modelde gömme derinliğinin kazı derinliğine, DH, oranıdır. Bağımsız değişkenler ilk modelde fi, $\mathrm{H}$, L1 iken ikinci modelde fi, H ve L1H' tır. Burada fi, içsel sürtünme açısını( $\phi) ; H$, kazı derinliğini; L1, yeraltı su seviyesini (YASS) ve $\mathrm{L} 1 \mathrm{H}$, yeraltı su seviyesinin kazı derinliğine oranıdır. Çoklu regresyon analizleri, SPSS Statistics v17.0 yardımı ile adım adım(stepwise) analiz kullanılarak gerçekleştirilmiştir. Bu yöntemde tüm bağımsız değişkenlerin bağımlı değişkenle ilişkileri ayrı ayrı incelenerek çeşitli kombinasyonlarda alt modeller kurulur ve en iyi model belirlenmeye çalış1lır. Bunun belirlenmesi için SPSS Statistics v17.0 öncelikle düzeltilmiş $\mathrm{R}^{2}$ değerini dikkate almaktadır ve bununla birlikte çalışma kapsamında MARE de kullanılmaktadır.

\section{Araștırma Sonuçları ve Tartışma}

Palplanş duvarların gömme derinliğini ve gömme derinliğinin kazı derinliğine oranını berlemek amacıyla kurulan iki model için elde edilen analiz sonuçları Tablo 1 ve Tablo 2' de, bu modellere ait en iyi alt modeller için elde edilmiş ifadeler Tablo 3 'te sunulmuştur. Modellerin tahmin başarısının belirlenmesi için programın verdiği $\mathrm{R}^{2}$ ve ikinci bir değerlendirme kriteri olarak hesaplanan ortalama mutlak relatif hata (MARE) değerleri de bu tablolarda verilmiştir.
Tablo 1' de görüldüğü üzere gömme derinliğini tahmin etmek için kurulan modellerden, fi, H ve L1 değişkenlerinin birlikte kullanıldığı model en başarılı sonucu vermektedir.

Tablo 1. Model 1'e ait çoklu regresyon analizi sonuçları

\begin{tabular}{|c|c|c|c|c|}
\hline $\begin{array}{c}\text { Model 1 } \\
\text { (D) }\end{array}$ & $\mathrm{R}$ & $\mathrm{R}^{2}$ & $\begin{array}{c}\text { Düzeltilmiş } \\
\mathrm{R}^{2}\end{array}$ & $\begin{array}{c}\text { Standart } \\
\text { Hata }\end{array}$ \\
\hline fi & .725 & .526 & .525 & 1.92893 \\
\hline fi-H & .908 & .824 & .823 & 1.17664 \\
\hline fi-H-L1 & .959 & .920 & .920 & .79190 \\
\hline
\end{tabular}

Tablo 2’ de görüldüğü üzere gömme derinliğinin kazı derinliğine oranını tahmin etmek için kurulan modellerden, fi ve L1H değişkenlerinin birlikte kullanıldığı model en başarılı sonucu vermektedir.

Tablo 2. Model 2'ye ait çoklu regresyon analizi sonuçları

\begin{tabular}{|c|c|c|c|c|}
\hline $\begin{array}{c}\text { Model 2 } \\
\text { (DH) }\end{array}$ & $\mathrm{R}$ & $\mathrm{R}^{2}$ & $\begin{array}{c}\text { Düzeltilmiş } \\
\mathrm{R}^{2}\end{array}$ & $\begin{array}{c}\text { Standart } \\
\text { Hata }\end{array}$ \\
\hline fi & .897 & .805 & .805 & .22883 \\
\hline fi-L1H & .973 & .946 & .946 & .12022 \\
\hline
\end{tabular}

Elde edilen çoklu regresyon denklemleri ile tahmin edilen ve teorik olarak hesaplanan D ve DH değerlerinin saçılımını ve bu saçılımı lineer olarak temsil eden doğruyu ve bu doğruya ait $\mathrm{R}^{2}$ değerini gösteren grafikler aşağıdaki gibidir (Şekil 5-6). Bu grafiklerde bu doğru ve eğrilere ait denklemler ve bu denklemlerin $\mathrm{R}^{2}$ değerleri de mevcuttur.

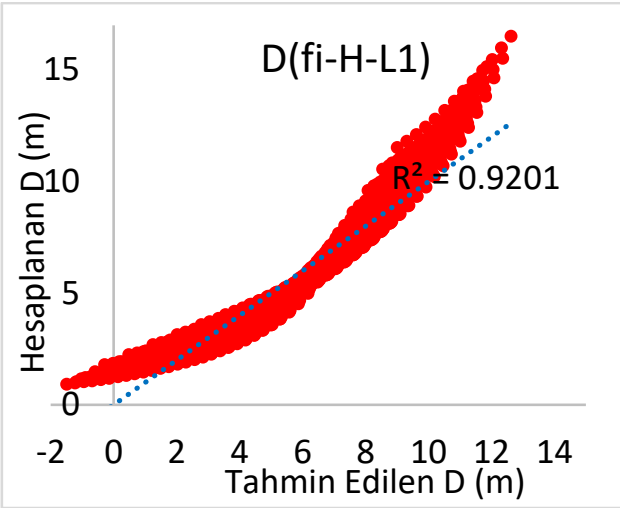

Şekil 5. Model 1'e ait tahmin edilen ve hesaplanan gömme derinliklerinin saçılımı

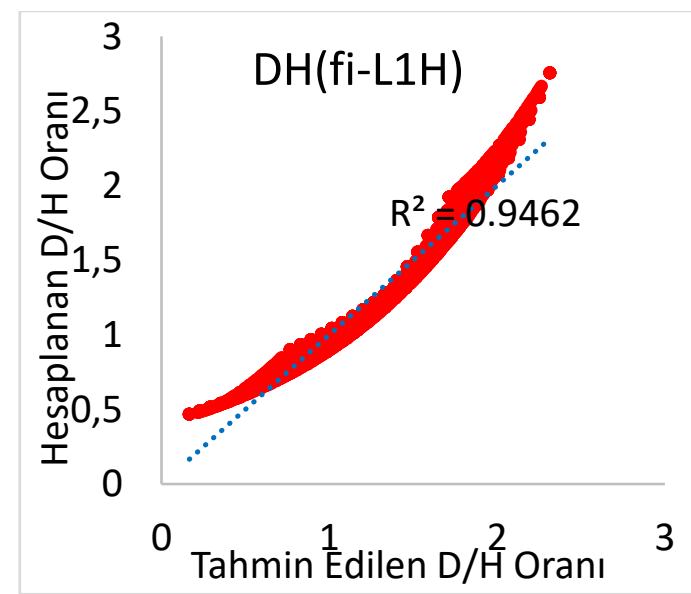

Şekil 6. Model 2'ye ait tahmin edilen ve hesaplanan gömme derinliği-kazı derinliği oranlarının saçılımı 
Model 1 için düzeltilmiş $\mathrm{R}^{2}$ değeri 0.92 iken MARE \%15.534 ve Model 2 için $\mathrm{R}^{2}$ değeri 0.946 iken MARE \%9.243' tür (Tablo 3). Bu sonuçlar, bağımsız değişken olarak $\mathrm{L} 1 \mathrm{H}$ ve bağımlı değişken olarak DH kullanılması durumunda elde edilen ifadenin tahmin yeteneğinin arttığını göstermektedir.

Tablo 3. Model 1 ve Model 2'ye ait regresyon denklemleri ve değişkenleri

\begin{tabular}{|c|c|c|c|c|c|}
\hline Model & $\begin{array}{l}\text { Bağımlı } 1 \\
\text { Değişken }\end{array}$ & \begin{tabular}{|c|} 
Bağımsız \\
Değişkenler
\end{tabular} & $\begin{array}{l}\text { Regresyon Denklemi } \\
(\mathrm{x})\end{array}$ & $\begin{array}{c}\text { MARE } \\
(\%)\end{array}$ & $\mathrm{R}^{2}$ \\
\hline Model 1 & $\mathrm{D}$ & fi-H-L1 & $\mathbf{D}=8.820-0.27065 * \mathbf{f i}+1.536821 * \mathbf{H}-0.60263 * \mathbf{L} \mathbf{1}$ & 15.534 & .920 \\
\hline Model 2 & $\mathrm{DH}$ & fi-L1H & DH $=3.555-0.062 *$ fi $-0.602 * \mathbf{L} 1 \mathbf{H}$ & 9.243 & .946 \\
\hline
\end{tabular}

\section{Sonuç}

Çalışma kapsamında, toplam 2106 adet kum zemine gömülü konsol palplanş duvar modelinin çözümleri Matlab R2015a yardımıyla gerçekleştirilmiş ve sonuçlar SPSS Statistics v 17.0 yardımıyla adım adım çoklu regresyon analizi gerçekleştirilerek gömme derinliğini tahmin edebilmek için denklemler elde edilmiştir. Elde edilen ifadelerin tahmin başarıları regresyon katsayıs1 $R^{2}$ ve bunun yanında ortalama mutlak relatif hata (MARE) ile belirlenmiştir. Buna göre aşağıdaki sonuçlar çıkarılabilir :

Çakma derinliğinin, D, içsel sürtünme açısı, yeraltı su seviyesi ve kazı derinliğini kullanarak tahmin edilebilirliği \%15.5 ortalama mutlak relatif hata ile mümkündür.

Çakma derinliğinin kazı derinliğine oranı, DH, içsel sürtünme açısı ve yeraltı su seviyesinin kazı derinliğine oranı kullanarak tahmin edilebilirliği $\% 9.2$ ortalama mutlak relatif hata ile mümkündür.

Çakma derinliği ile ilgili ifade elde edilirken, bağımlı değişken olarak gömme derinliği yerine, gömme derinliğinin kazı derinliğine oranını ve bağımsız değişken olarak da yeraltı su seviyesi yerine, yeraltı su seviyesinin kazı derinliğine oranını kullanmak tahmin başarısını \% 40 civarında artırmaktadır.

\section{Kaynakça}

Akbay, Z., Dalyan, İ., Akın, M. S., \& Gençdal, H. B. (2020). An Application of TBEC-2018 in the Prediction of Retaining Wall Dimensions with Simple Regression Analysis. Global Journal in Civil Engineering, 2(2).

Bolton, M. D., Powrie, W., \& Symons, I. F. (1989). The design of stiff in-situ walls retaining over consolidated clay-Part I: short-term behaviour. Ground Engineering, 22(8), 4447.

Bolton, M. D., Powrie, W., \& Symons, I. F. (1990a). The design of stiff in-situ walls retaining over consolidated clay-Part II: long-term behaviour (continued). Ground Engineering, 23(2), 22-28.

Bolton, M. D., Powrie, W., \& Symons, I. F. (1990b). The design of stiff in-situ walls retaining over consolidated clay-Part II: short-term behaviour (continued). Ground Engineering, 22(9), 34-40.

Bransby, J. E., \& Milligan, G. W. E. (1975). Soil Deformations near Cantilever Retaining Walls. Geotechnique, 24(2), 175-195.

Chantana, J., Kawano, Y., Kamei, A., \& Minemoto, T. (2019). Description of degradation of output performance for photovoltaic modules by multiple regression analysis based on environmental factors. Optik, 179, 1063-1070. https://doi.org/10.1016/J.IJLEO.2018.11.040

Choi, M., \& Lee, G. (2010). Decision tree for selecting retaining wall systems based on logistic regression analysis. Automation in Construction, 19(7), 917-928. https://doi.org/10.1016/J.AUTCON.2010.06.005

Choudry, D., Singh, S., \& Goel, S. (2006). New approach for analysis of cantilever sheet pile with line load. Journal of Geotechnical and Geoenvironmental Engineering, 43(5), 540-549.

Coduto, D. P. (2001). Foundation Design: Principles and Practices. Prentice Hall.

Dagdeviren, U., \& Kaymak, B. (2020). A regression-based approach for estimating preliminary dimensioning of reinforced concrete cantilever retaining walls. Structural and Multidisciplinary Optimization, 61(4), 1657-1675. https://doi.org/10.1007/s00158-019-02470-w

Das, B. M. (2007). Principles of Foundation Engineering, 6th Edition. Brooks/Cole Publishing Company.

Das, B. M. (2014). Principles of Foundation Engineering. Cengage Learning.

Gajan, S. (2011). Normalized Relationships for Depth of Embedment of Sheet Pile Walls and Soldier Pile Walls in Cohesionless Soils. Soils and Foundations, 51(3), 559564. https://doi.org/10.3208/SANDF.51.559

Hagerty, D. J., \& Nofal, M. M. (1992). Design aids-anchored bulkheads in sand. Canadian Geotechnical Journal, 29(5), 789-795.

Olmschenk, G., Zhu, Z., \& Tang, H. (2019). Generalizing semisupervised generative adversarial networks to regression using feature contrasting. Computer Vision and Image Understanding, 186, 1-12. https://doi.org/10.1016/J.CVIU.2019.06.004

Polat, Ö. (2015). A robust regression based classifier with determination of optimal feature set. Journal of Applied Research and Technology. JART, 13(4), 443-446. https://doi.org/10.1016/J.JART.2015.08.001

Powrie, W. (1997). Soil Mechanics: Concepts and Applications. E and FN Spon, An imprint of Chapman and Hall.

Rankine, W. J. (1857). II. On the stability of loose earth. Philosophical Transactions of the Royal Society of London, 147, 9-27.

Rowe, P. W. (1952). Anchored Sheet-pile walls. Proceedings of the Institution of Civil Engineers, 1(1), 27-70. https://doi.org/10.1680/iicep.1952.10942

Rowe, P. W. (1951). Cantilever sheet piling in cohesionless soil. Engineering, 316-319.

Sato-Ilic, M. (2017). Knowledge-based Comparable Predicted Values in Regression Analysis. Procedia Computer Science, 114, 216-223. 
https://doi.org/10.1016/J.PROCS.2017.09.063

Sitharam, T. G. (2013). Advanced Foundation Engineering. Indian Institute of Science.

Srivastava, A., \& Malhotra, M. (2016). Earth Pressure behind a Retaining Wall under Linearly Varying Geotechnical Parameters. Indian Journal of Science and Technology, 9(Special Issue 1), 1-8. https://doi.org/10.17485/IJST/2016/V9IS1/105809

Zhang, J., \& Thomas, L. C. (2012). Comparisons of linear regression and survival analysis using single and mixture distributions approaches in modelling LGD. International Journal of Forecasting, 28(1), 204-215.

https://doi.org/10.1016/J.IJFORECAST.2010.06.002 